\title{
Immune Characteristics of Children With Autoimmune Encephalitis and the Correlation With Short-term Prognosis
}

\author{
Jin-Yue HUANG \\ Tianjin Children's Hospital \\ Wen-Xuan FAN \\ Tianjin Children's Hospital \\ Jing MENG \\ Tianjin Children's Hospital \\ Chun-Quan CAI \\ Tianjin Children's Hospital \\ Dong LI ( $\square$ huanyj99@163.com ) \\ Tianjin Children's Hospital
}

\section{Research}

Keywords: autoimmune encephalitis, children, immunity, short-term prognosis, correlation

Posted Date: October 25th, 2021

DOI: https://doi.org/10.21203/rs.3.rs-988697/v1

License: @ (i) This work is licensed under a Creative Commons Attribution 4.0 International License. Read Full License 


\section{Abstract}

Objective: To explore the immune characteristics and short-term prognosis of children with autoimmune encephalitis $(\mathrm{AE})$, then to analyse the relationship between them.

Methods: A total of 78 children with AE were identified through the clinic database and inpatient consults in Tianjin Children's Hospital (238 Long-Yan Road, Bei-Chen District, Tianjin, China) from January 2018 to January 2021. Based on the recent follow-up (one-year follow-up) of the modified Rankin Scale (mRS) prognosis score, they were divided into a good prognosis group (59 cases, mRS $<3$ points) and a poor prognosis group (19 cases, $\mathrm{mRS} \geq 3$ points). The immune function characteristics of the two groups of children with $\mathrm{AE}$ were compared using Spearman correlation to analyse the $\mathrm{mRS}$ score and immune function indicators (IgA, IgG, IgM, CD4, CD8, CD4/CD8), and using binary logistic regression to analyse the factors affecting the prognosis of children with $\mathrm{AE}$.

Results: The differences in age, consciousness disorder, limb dyskinesia, cognitive impairment, onset type, mRS score at admission, and immune function status during remission between the two groups were statistically significant $(p<0.05)$. The mRS score of the good prognosis group at admission was significantly lower than that of the poor prognosis group $(2.65 \pm 0.76$ vs $3.05 \pm 0.71, p \otimes 0.05)$. $\lg \mathrm{A}(0.61 \pm 0.19$ vs $0.87 \pm$ $0.25, p<0.001)$, IgG $(8.17 \pm 1.12$ vs $9.02 \pm 1.39, p=0.001)$. $\operatorname{lgM}(1.01 \pm 0.26$ vs $1.23 \pm 0.33, p<0.001)$ in the good prognosis group were significantly lower than those in the poor prognosis group, while CD4 (36.35 \pm 8.74 vs $23.89 \pm 6.97, p<0.001)$ and $\operatorname{CD} 4 / C D 8(1.68 \pm 0.32$ vs $1.01 \pm 0.24, p=0.001)$ were significantly higher than those in the poor prognosis group. Spearman correlation analysis showed that the mRS score at admission was significantly negatively correlated with CD4/CD8 $(r \otimes-0.775, p<0.001)$, but not significantly correlated with other immune function indexes. Binary logistic regression showed that age $(O R=0.385 ; 95 \%$ $\mathrm{Cl}=0.200-0.741)$, consciousness disorder $(\mathrm{OR}=39.3569 ; 95 \% \mathrm{Cl}=4.073-380.262)$, limb movement disorder $(\mathrm{OR}=17.107 ; 95 \% \mathrm{Cl}=2.769-105.701)$, and abnormal immune function in remission $(\mathrm{OR}=0.050 ; 95 \% \mathrm{Cl}=$ 0.007-0.372) were risk factors for poor prognosis in children with $A E$.

Conclusion: There is a close correlation between $\mathrm{mRS}$ and immune function index CD4/CD8 in children with AE when they are admitted to the hospital. Young age, disturbance of consciousness, limb dyskinesia, and abnormal immune function in remission are risk factors for poor prognosis of children with AE. More attention should be paid in clinical treatment.

\section{Introduction}

Autoimmune encephalitis $(\mathrm{AE})$ is encephalopathy mediated by an antigenic immune response in the central nervous system. ${ }^{[1]} \mathrm{AE}$ is the third most common cause of encephalitis; the first and second are infectious encephalitis and acute disseminated encephalomyelitis. ${ }^{[2]}$ Most patients with AE have a cognitive impairment, acute or subacute seizures and other clinical manifestations. ${ }^{[3]}$ The clinical presentations are complex and diverse. For example, some patients have no obvious abnormalities in radiologic features, such as magnetic resonance imaging (MRI) ${ }^{[4]}$ However, the diagnosis and treatment of children with $\mathrm{AE}$ is still an enormous challenge, and it may cause adverse effects on the recovery and prognosis of patients. ${ }^{[5]}$ At present, the pathogenesis of $A E$ is not clear. Some mathematicians propose that the occurrence of $A E$ is related to 
immune function. The clinical brain injury of patients causes irreversible performance, and the prognosis is poor. Most of the research related to $\mathrm{AE}$ is focused on early diagnosis, treatment and prognosis analysis. However, there has been little research on studying the characteristics of immune function, and the relationship between immune function and prognosis of patients with $A E$ needs to be studied further. ${ }^{\left[{ }^{[6]}\right.}$ Therefore, this study aims to analyse the clinical features, humoral immunity, cellular immunity, and the shortterm prognosis of $\mathrm{AE}$ in children to provide more reference for clinical prognosis evaluation.

\section{Methods}

\section{Patients}

This is a retrospective case series of paediatric patients ( $<18$ years) who were evaluated for $A E$ at the Tianjin Children's Hospital (238 Long-Yan Road, Bei-Chen District, Tianjin, China) between January 2018 and January 2021. Cases were identified through the clinic database and inpatient consults. Informed consent from the parents and assent from the patients were obtained. The included patients fulfilled the diagnostic criteria for

AE in paediatric patients. ${ }^{[7-8]}$ This study was conducted in accordance with the Declaration of Helsinki (as revised in 2013) and approved by the ethics committee of Tianjin Children's Hospital.

Patients with cerebral haemorrhage, cerebral infarction, brain tumours, congenital brain hypoplasia and other infectious diseases were excluded. The case definition was the following: diagnosed as a positive autoimmune encephalitis-related antibody in cerebrospinal fluid; accompanied with obvious mental and memory disorders and seizures and other symptoms or clinical syndrome; any patients with a follow-up more than one year; auxiliary examination, treatment, and other clinical data were complete.

\section{Procedures}

Data recorded included demographic characteristics, clinical presentation, diagnostic workup including laboratory studies, course and duration of treatment, response to treatment, and short-term outcome. We defined first-line immunotherapy to include high-dose corticosteroids, intravenous immunoglobulin, and plasma exchange and second-line immunotherapy as rituximab, cyclophosphamide, or mycophenolate mofetil. The auxiliary examination was made as follows: the blood of the empty abdomen vein was $3 \mathrm{ml}$, and the serum was separated by centrifugation for 30 minutes with $3000 \mathrm{r} /$ minutes, and the supernatant was taken. The serum IgA, IgG and IgM were measured by immunoturbidimetry. The levels of T-lymphocyte subsets (CD3, CD4, CD8, CD4/CD8) in peripheral blood were measured by flow cytometry. According to the modified Ranking Scale (mRS), we divided patients with a follow-up of one year into two groups: $m R S<3$ were in the good prognosis group, and $\mathrm{mRS} \geq 3$ were in the poor prognosis group.

\section{Statistical analysis}

Data processing and descriptive statistical analysis were performed using SPSS version 22.0. According to the normality test, the results are described as mean $\pm \mathrm{SD}(\overline{\mathrm{x}} \pm \mathrm{s}$ ) or median (interquartile range). The comparison between groups was completed by a Students' Unpaired t-test. Categorical data were described 
as $n(\%)$, the comparison between groups was performed by $\chi^{2}$ test or exact probability test. The influencing factors of prognosis were analysed by a binary logistic regression model. Spearman correlation analysis was used to analyse the relationship between mRS prognosis score and an immune function index. $p<0.05$ indicated statistical significance.

\section{Results}

\section{Comparison of clinical data between the two groups}

We identified 78 patients presenting with features consistent with $A E$, of which 47 (60.26\%) were male. These features were based on the proposed diagnostic criteria for $A E$ in children and the modified Ranking Scale (mRS). There were 59 patients in the good prognosis group with a mean age of $7.29 \pm 1.26$ years; 34 (57.63\%) were male. In the poor prognosis group, there were 19 patients with a mean age of $5.73 \pm 1.46$ years; 13 (68.42\%) were male.

The clinical presentation of patients was different, with 29 patients (37.18\%) suffering from limb dyskinesia. The poor prognosis group had a higher proportion of limb dyskinesia than the good prognosis group (63.16\% vs $28.81 \%, p=0.007$ ). A total of 31 patients suffered from consciousness disorder, of which 13 patients $(68.42 \%)$ were in the poor prognosis group. The proportion of consciousness disorder was higher than in the good prognosis group with $30.51 \%(p=0.003)$. The most common presenting symptoms were mental behaviours (83.3\%). Four patients were accompanied with cognitive impairments. All were in the poor prognosis group. In the good prognosis group, $72.88 \%$ of the patients had an infection onset, followed by fever, vomiting, headache, and cough, which accounted for $64.41 \%, 38.98 \%, 44.07 \%$, and $52.54 \%$, respectively. In the negative antibody group, $52.54 \%$ of patients had an infection onset, followed by fever, vomiting, headache, cough, which accounted for $52.63 \%, 42.11 \%, 36.84 \%$, and $42.11 \%$, respectively. In terms of the type of disease, 55 patients had acute onset, while 23 patients had subacute onset. It seemed that patients in the poor prognosis group suffered from a longer course of disease than patients in the good prognosis group. After the diagnosis, 33 patients received treatment of low-dose glucocorticoid therapy. A total of 20 patients received treatment of high-dose glucocorticoid therapy. There were 25 patients treated with gamma globulin. Except for high-dose glucocorticoid therapy, the good prognosis group showed a higher proportion of immunological therapy than the poor prognosis group $(p=0.761)$ (Table 1$)$. 
Table 1

Comparison of demographic and clinical Features of AE Patients between the two groups

\begin{tabular}{|c|c|c|c|c|}
\hline Variables & $\begin{array}{l}\text { Good prognosis } \\
\text { group }(n=59)\end{array}$ & $\begin{array}{l}\text { Poor prognosis } \\
\text { group }(n=19)\end{array}$ & Value & $P$ value \\
\hline Age, $\bar{x} \pm s$ & $7.29 \pm 1.65$ & $5.73 \pm 1.46$ & 3.680 & $<0.001^{*}$ \\
\hline Gender, $n(\%)$ & & & 0.699 & 0.403 \\
\hline Male & $34(57.63)$ & $13(68.42)$ & & \\
\hline Female & $25(42.37)$ & $6(31.58)$ & & \\
\hline \multicolumn{5}{|l|}{ Clinical features, $n(\%)$} \\
\hline Mental behaviors & $48(81.36)$ & 17(89.47) & 0.682 & 0.409 \\
\hline Consciousness Disorder & $18(30.51)$ & $13(68.42)$ & 8.626 & $0.003^{\star}$ \\
\hline Limb dyskinesia & $17(28.81)$ & 12(63.16) & 7.258 & $0.007^{\star}$ \\
\hline Sleep disorders & $18(30.51)$ & $8(42.11)$ & 0.870 & 0.351 \\
\hline Autonomic nervous Dysfunction & 12(20.34) & $6(31.58)$ & 1.023 & 0.312 \\
\hline Language barrier & $9(15.25)$ & $5(26.32)$ & 1.194 & 0.275 \\
\hline Memory loss & $9(15.25)$ & $4(21.05)$ & 0.348 & 0.555 \\
\hline Cognitive impairment & $0(0.00)$ & $4(21.05)$ & - & $0.013^{\star}$ \\
\hline \multicolumn{5}{|l|}{ Premonitory symptom, $n(\%)$} \\
\hline Infection & $43(72.88)$ & $11(57.89)$ & 1.515 & 0.218 \\
\hline Fever & $38(64.41)$ & $10(52.63)$ & 0.842 & 0.359 \\
\hline Esise & 23(38.98) & $8(42.11)$ & 0.059 & 0.809 \\
\hline Headache/dizziness & $26(44.07)$ & $7(36.84)$ & 0.307 & 0.579 \\
\hline Cough & $31(52.54)$ & $8(42.11)$ & 0.626 & 0.429 \\
\hline Stomachache/diarrhea & $33(55.93)$ & 12(63.16) & 0.307 & 0.579 \\
\hline \multicolumn{5}{|l|}{ Onset type, $n(\%)$} \\
\hline acute & $37(62.71)$ & 18(94.74) & 7.089 & $0.008^{*}$ \\
\hline subacute & $22(37.29)$ & $1(5.26)$ & & \\
\hline mRS score at admission, $n(\%)$ & & & 5.761 & $0.016^{*}$ \\
\hline$\geq 3$ score & $28(47.46)$ & 15(78.95) & & \\
\hline$<3$ score & $31(52.54)$ & $4(21.05)$ & & \\
\hline MRI abnormalities, $n$ (\%) & $36(61.02)$ & $14(73.68)$ & 1.002 & 0.317 \\
\hline
\end{tabular}




\begin{tabular}{|lllll|}
\hline Variables & $\begin{array}{l}\text { Good prognosis } \\
\text { group(n=59) }\end{array}$ & $\begin{array}{l}\text { Poor prognosis } \\
\text { group(n=19) }\end{array}$ & Value & P value \\
\hline CSF abnormalities, $n(\%)$ & $33(55.93)$ & $13(68.42)$ & 0.926 & 0.336 \\
\hline EEG abnormalities, $n(\%)$ & $47(79.66)$ & $17(89.47)$ & 0.940 & 0.332 \\
\hline $\begin{array}{l}\text { Immune function status in } \\
\text { remission, } n(\%)\end{array}$ & & & 9.749 & $0.002^{*}$ \\
\hline Normal & $47(79.66)$ & $8(42.11)$ & & \\
\hline Abnormal & $12(20.34)$ & $11(57.89)$ & & 0.547 \\
\hline Immunological therapy, $n(\%)$ & & & & 0.761 \\
\hline a & $26(44.07)$ & $7(36.84)$ & & \\
\hline b & $14(23.73)$ & $6(31.58)$ & & \\
\hline c & $20(33.9)$ & $5(26.31)$ & & \\
\hline
\end{tabular}

Abbreviations: mRS. modified Rankin Scale; MRI. magnetic resonance imaging; CSF. cerebrospinal fluid; EEG. Electroencephalographic; a. low-dose glucocorticoid therapy; b. high-dose glucocorticoid therapy; c. gamma globulin

\section{Comparison of mRS scores at admission between two groups}

The mRS score of the good prognosis group at admission was significantly lower than that of the poor prognosis group ( $2.65 \pm 0.76$ vs $3.05 \pm 0.71)$, and the difference was statistically significant $(p<0.05)$ (Figure 1).

\section{Comparison of immune function indexes at admission between two groups}

There was no significant difference in CD8 between the two groups. IgA, IgG and IgM in the good prognosis group were significantly lower than those in the poor prognosis group $(p<0.001, p=0.001, p<0.001)$, while CD4 and CD4/CD8 were significantly higher than those in the poor prognosis group $(p<0.001, p=0.001)$ (Table 2).

Table 2

Comparison of immune function indexes at admission between two groups

\begin{tabular}{|lcclllll|}
\hline Group & $\mathbf{n}$ & $\operatorname{lgA}\left(\mathrm{g}^{\star} \mathrm{L}^{-1}\right)$ & $\operatorname{lgG}\left(\mathrm{g}^{*} \mathrm{~L}^{-1}\right)$ & $\operatorname{lgM}\left(\mathrm{g}^{*} \mathrm{~L}^{-1}\right)$ & $\mathrm{CD} 4\left(\mathrm{~g}^{*} \mathrm{~L}^{-1}\right)$ & $\mathrm{CD} 8\left(\mathrm{~g}^{*} \mathrm{~L}^{-1}\right)$ & $\mathrm{CD} 4 / \mathrm{CD} 8$ \\
\hline $\begin{array}{l}\text { Good } \\
\text { prognosis } \\
\text { group }\end{array}$ & 59 & $0.61 \pm 0.19$ & $8.17 \pm 1.12$ & $1.01 \pm 0.26$ & $36.35 \pm 8.74$ & $22.38 \pm 7.65$ & $1.68 \pm 0.32$ \\
\hline $\begin{array}{l}\text { Poor prognosis } \\
\text { group }\end{array}$ & 19 & $0.87 \pm 0.25$ & $9.02 \pm 1.39$ & $1.23 \pm 0.33$ & $23.89 \pm 6.97$ & $22.73 \pm 6.36$ & $1.01 \pm 0.24$ \\
\hline Value & - & 5.855 & 3.367 & 3.703 & 7.881 & 0.249 & 3.446 \\
\hline Pvalue & - & $<0.001$ & 0.001 & $<0.001$ & $<0.001$ & 0.804 & 0.001 \\
\hline
\end{tabular}




\section{Correlation analysis between immune function indexes and mRS scores at admission between two groups}

Spearman correlation analysis was used to analyse the relationship between mRS score at admission and immune function indexes with a statistical difference. The results showed that in 78 patients, the mRS score at admission was significantly negatively correlated with CD4/CD8 $(r=-0.775, p<0.001)$. For patients in the good prognosis group, the mRS score at admission was negatively correlated with CD4/CD8 $(r=-0.834, p<$ $0.001)$. For patients in the poor prognosis group, the mRS score at admission was negatively correlated with $\mathrm{CD} 4 / \mathrm{CD} 8(r=-0.470, p=0.043)$. For different samples, there was no significant correlation between $\mathrm{mRS}$ score and $\lg \mathrm{A}$, IgG, IgM, and CD4. Spearman correlation analysis showed that the mRS score at admission was significantly negatively correlated with $\operatorname{CD} 4 / C D 8(p<0.05)$ but not significantly correlated with other immune function indexes (Table 3).

Table 3

Spearman correlation analysis between immune function indexes and mRS scares at admission among two group

\begin{tabular}{|c|c|c|c|c|c|c|}
\hline \multirow[t]{2}{*}{ Immune function index } & \multicolumn{2}{|c|}{78 children with $\mathrm{AE}$} & \multicolumn{2}{|c|}{ The good prognosis group } & \multicolumn{2}{|c|}{ The poor prognosis group } \\
\hline & rvalue & $P$ value & rvalue & $P$ value & rvalue & $P$ value \\
\hline $\lg A$ & 0.221 & 0.052 & 0.117 & 0.377 & 0.127 & 0.605 \\
\hline $\lg G$ & 0.131 & 0.253 & -0.013 & 0.920 & -0.001 & 0.995 \\
\hline $\lg M$ & 0.172 & 0.132 & 0.178 & 0.176 & 0.148 & 0.545 \\
\hline CD4 & 0.013 & 0.097 & 0.184 & 0.163 & 0.093 & 0.704 \\
\hline CD4/CD8 & -0.775 & $<0.001$ & -0.834 & $<0.001$ & -0.470 & 0.043 \\
\hline
\end{tabular}

\section{Analysis of influencing factors of poor prognosis in child patients}

Analysis of influencing factors of poor prognosis in children with acute disturbance syndrome were independent variables: age, consciousness disorder ( $1=$ yes, $2=$ none), limb motor disorder $(1=$ yes, $2=$ none), cognitive impairment ( $1=$ yes, $2=$ none), mRS score at admission, and immune function state ( $1=$ normal, 2 = abnormal) after admission. There is a correlation between $\mathrm{mRS}$ and immune function index $\mathrm{CD} 4 / \mathrm{CD} 8$ in children with $\mathrm{AE}$ when they are admitted to the hospital. Young age $(\mathrm{OR}=0.385 ; 95 \% \mathrm{Cl}$ $0.200 \sim 0.741$ ), disturbance of consciousness (OR = 39.3569; 95\% Cl 4.073 380.262), limb dyskinesia ( $\mathrm{OR}=$ $17.107 ; 95 \% \mathrm{Cl} 2.769 \sim 105.701)$, and abnormal immune function ( $\mathrm{OR}=0.050 ; 95 \% \mathrm{Cl} 0.007 \sim 0.372$ ) in remission are risk factors for poor prognosis of children with $\mathrm{AE}$ (Table 4). 
Table 4

Multivariate binary logistic regression analysis of poor prognosis in children with $\mathrm{AE}$

\begin{tabular}{|llllll|}
\hline Variables & B & S.E. & Wald & P value & OR(95\%Cl) \\
\hline age & -0.956 & 0.335 & 8.159 & 0.004 & $0.385(0.200 \sim 0.741)$ \\
\hline Disturbance-of-cosciousness & 3.673 & 1.157 & 10.071 & 0.002 & $39.356(4.073 \sim 380.262)$ \\
\hline Limb dyskinesia & 2.839 & 0.929 & 9.339 & 0.002 & $17.107(2.769 \sim 105.701)$ \\
\hline Immune function status in remission & -2.999 & 1.026 & 8.538 & 0.003 & $0.050(0.007 \sim 0.372)$ \\
\hline constant & 3.648 & 1.957 & 3.474 & 0.062 & - \\
\hline
\end{tabular}

\section{Discussion}

In the past, children with viral encephalitis were common in clinics. ${ }^{[4,9]}$ The clinical presentations were mainly classified into types, including mental symptoms, epileptic seizures, motor disorders, language disorders, sleep disorders, autonomic nervous dysfunction and ventilation disorders. ${ }^{[10]}$ The duration of the disease could be several months or more, which was costly, and the lesions often involved the limbic system, mainly the cingulate gyrus, hippocampus and frontal lobe. ${ }^{[11,12]}$ Previously, it was diagnosed as sporadic encephalitis. However, in recent years, studies have found that the disease is closely associated with a variety of autoantibodies, which has been regarded as a common autoimmune disease. The involved part of the brain parenchyma went beyond the limbic system and was later called AE. It involved many parts of the central nervous system. ${ }^{[13]}$

Compared with adult patients with $\mathrm{AE}$, there were significant differences in clinical presentation, antibody levels, treatment and prognosis of children with $A E{ }^{\left[{ }^{[14]}\right.}$ The children with AE showed different types of clinical presentation, as mentioned above. ${ }^{[10]}$ Infection and fever were mainly prodromal symptoms. EEG monitoring is necessary for children with AE. In this study, more than $80 \%$ of the EEG was abnormal. These showed unilateral or bilateral epileptic activity focus and focal/extensive slow waves. Cerebrospinal fluid examination showed that about $60 \%$ of children with AE had a mild increase of lymphocytes, but the total number of lymphocytes was usually in the range of $100 / \mathrm{ul}$ and no more than $150 \mathrm{mg} / \mathrm{dl}$. The protein content may increase slightly, but the sugar content still maintains a normal level. For patients with or without inflammatory changes in cerebrospinal fluid (CSF), 70\% 80\% showed high signal intensity, asymmetry and unilateral abnormal lesions on flair or T2 images, and other parts could be involved. AE refers to a disease in which the immune system of the body responds to the antigens and antibodies produced by central nervous system antigens, resulting in central nervous system damage. With the increasing understanding of $A E$, related reports are present from time to time. For children with suspected $A E$, serum and cerebrospinal fluid antibody tests, brain MRI and EEG examinations, and systemic tumour screening should be carried out as soon as possible. Suitable treatment should be carried out immediately to obtain a good prognosis. After hospitalisation, 75.64\%(59/78)child patients basically recovered and were normally discharged according to the recent (one-year) follow-up according to the $\mathrm{mRS}$ score. This was consistent with $80 \%$ of the expert consensus. $^{[14]}$ 
The pathogenesis of $A E$ has not been clear. Previous studies have shown that $A E$ is associated with virus infection, tumour or autoimmunity. ${ }^{[15,16]}$ Since the concept of 'borderline encephalitis' was put forward in 1968, researchers from home or abroad have found related autoantibodies, such as Huanti body and antiglutamate dehydrogenase antibody. In addition, some studies pointed out that the occurrence of AE was also associated with antithyroid antibodies. ${ }^{[17]}$ It is suggested that the pathogenesis of AE is closely related to autoimmune dysfunction. Therefore, this study reviewed the clinical database of 78 children with $A E$, according to the recent follow-up mRS score (prognosis), to explore the relationship between humoral immune function, cellular immune function and the short-term prognosis of children with AE.

Humoral immunity is a specific immunity, mainly caused by the production of corresponding antibodies by Blymphocyte under the stimulation of antigens. When an antigen enters the body, B-lymphocyte will be sensitised under its stimulation, accelerating the value-added and differentiation, and producing corresponding antibodies, referred to as immunoglobulin. According to the composition and structure, immunoglobulins can be divided into five categories: $\lg A, \lg M, \lg G, \lg D$ and $\lg E$. Among them, $\lg A, \lg M$ and $\lg G$ levels can be used as important indicators to evaluate humoral immune function. ${ }^{[18,19]}$ T-lymphocytes mainly mediate cellular immunity and, at the same time, can regulate humoral immunity. There are many CD molecules on the surface of T-cells, such as CD3, CD4, and CD8, which are widely involved in the whole process of T-cell recognition, activation and proliferation, apoptosis, and elimination of allogeneic antigen. ${ }^{[20]}$ The surface antigen of T-lymphocytes can be divided into a CD4 subgroup and a CD8 subgroup. CD4 cells and CD 8 cells coordinate and restrict each other under normal physiological conditions, and the ratio of CD4/CD 8 is in dynamic equilibrium. When the dynamic balance is broken, the ratio of CD4/CD8 is decreased, which indicates that the immune regulatory network is out of balance and the immune function is decreased. In the low immune state, the decrease of CD4 content and CD4/CD8 ratio can further stimulate B-lymphocytes to secrete antibodies, form immune complexes, and activate complements, which may cause a variety of diseases. $^{[21]}$

In this study, humoral immunity and cellular immune levels of the two groups of children with $A E$ found that the two groups had great differences in remission immune function. Abnormal immune status in poor $A E$ (57.89\%) was significantly higher than in good AE (20.34\%), and the two groups were significantly different. The IgA, IgG, IgM, CD4, and CD4/CD8 levels in children with good prognosis were significantly better than in children with poor prognosis. It was suggested that overall hyperthyroidism of humoral immunity in $A E$ in children with poor prognosis was more obvious than in children with a good prognosis. There was a significant negative correlation between $\mathrm{mRS}$ score and CD4/CD8 at admission, which suggested that there was a close relationship between immune function and prognosis. In addition, this study analysed the factors affecting the prognosis of children with $\mathrm{AE}$ and found that young age, disturbance of consciousness, limb movement disorder and abnormal immune function in remission stage were the risk factors for poor prognosis of children with $A E .^{[22-24]}$ Other risk factors were consistent with previous studies except for the younger age. However, there is no statistical data on the population and age of children with high incidence. In this study, young age was the risk factor for the conclusion. The reasons may be as follows: (1) AE accounted for about $10 \% \sim 20 \%$ of all encephalitis, and this study had a small sample size, resulting in inconsistent conclusions; (2) compared with older children, the immune function of young children is weaker, and the immune network is more likely to be unbalanced, which leads to poor prognosis. Because of the small sample 
size, the varied response to therapy in our study could be explained with different autoimmune encephalitis antibodies, making it difficult to draw conclusions from each group.

\section{Conclusion}

There is a close relationship between immune function and the prognosis of children with AE. A younger age, consciousness disorder, limb movement disorder and immune dysfunction in the remission stage are risk factors for poor prognosis for children with AE. There are no age-related data in the existing epidemiology. The younger age is a risk factor, which may be related to the weak immune status of young children.

\section{Declarations}

\section{Ethics approval and consent to participate}

This study was conducted in accordance with the Declaration of Helsinki and approved by the ethics committee of Tianjin Children's Hospital.

\section{Consent for publication}

Not applicable.

\section{Availability of data and materials}

All data generated or analyzed during this study are included in this published article

\section{Competing interests}

All of the authors had no any personal, financial, commercial, or academic conflicts of interest separately.

\section{Funding}

This study was supported by the Tianjin special project of science and technology for major disease prevention and control, China, Grant Number:[18ZXDBSY00170]

\section{Authors' contributions}

J.Y. , W.X. conceived of the study, and J.M. and C.Q. participated in its design and coordination and D. L. helped to draft the manuscript. All authors read and approved the final manuscript.

\section{Acknowledgements}

We are particularly grateful to all the people who have given us help on our article.

\section{References}

1. Rutatangwa A, Mittal N, Francisco C, Nash K, Waubant E. Autoimmune Encephalitis in Children: A Case Series at a Tertiary Care Center. J Child Neurol. 2020 Aug;35(9):591-599. doi: 
10.1177/0883073820923834. Epub 2020 May 27. PMID: 32458722.

2. Granerod J, Ambrose HE, Davies NW, Clewley JP, Walsh AL, Morgan D, Cunningham R, Zuckerman M, Mutton KJ, Solomon T, Ward KN, Lunn MP, Irani SR, Vincent A, Brown DW, Crowcroft NS; UK Health Protection Agency (HPA) Aetiology of Encephalitis Study Group. Causes of encephalitis and differences in their clinical presentations in England: a multicentre, population-based prospective study. Lancet Infect Dis. 2010 Dec;10(12):835-44. doi: 10.1016/S1473-3099(10)70222-X. Epub 2010 Oct 15. Erratum in: Lancet Infect Dis. 2011 Feb;11(2):79. PMID: 20952256.

3. Aksamit AJ Jr. Treatment of Viral Encephalitis. Neurol Clin. 2021 Feb;39(1):197-207. doi: 10.1016/j.ncl.2020.09.011. Epub 2020 Nov 7. PMID: 33223083.

4. Seniaray N, Verma R, Ranjan R, Belho E, Mahajan H. 18F-FDG PET/CT in Initial Diagnosis and Treatment Response Evaluation of Anti-NMDAr and Anti-GAD Dual Antibody Autoimmune Encephalitis. Clin Nucl Med. 2021 Jan;46(1):e63-e64. doi: 10.1097/RLU.0000000000003379. PMID: 33181746.

5. Favier M, Joubert B, Picard G, Rogemond V, Thomas L, Rheims S, Bailhache M, Villega F, Pédespan JM, Berzero G, Psimaras D, Antoine JC, Desestret V, Honnorat J. Initial clinical presentation of young children with N-methyl-d-aspartate receptor encephalitis. Eur J Paediatr Neurol. 2018 May;22(3):404-411. doi: 10.1016/j.ejpn.2017.12.014. Epub 2017 Dec 28. PMID: 29310866.

6. Morano A, Fanella M, Cerulli Irelli E, Barone FA, Fisco G, Orlando B, Albini M, Fattouch J, Manfredi M, Casciato S, Di Gennaro G, Giallonardo AT, Di Bonaventura C. Seizures in autoimmune encephalitis: Findings from an EEG pooled analysis. Seizure. 2020 Dec;83:160-168. doi: 10.1016/j.seizure.2020.10.019. Epub 2020 Oct 31. PMID: 33161244.

7. Lohse AW. Diagnostic Criteria for Autoimmune Hepatitis: Scores and More. Dig Dis. 2015;33 Suppl 2:4752. doi: 10.1159/000440709. Epub 2015 Dec 7. PMID: 26641924.

8. Cellucci T, Van Mater H, Graus F, Muscal E, Gallentine W, Klein-Gitelman MS, Benseler SM, Frankovich J, Gorman MP, Van Haren K, Dalmau J, Dale RC. Clinical approach to the diagnosis of autoimmune encephalitis in the pediatric patient. Neurol Neuroimmunol Neuroinflamm. 2020 Jan 17;7(2):e663. doi: 10.1212/NXI.0000000000000663. Erratum in: Neurol Neuroimmunol Neuroinflamm. 2020 Apr 15;7(4): PMID: 31953309; PMCID: PMC7051207.

9. Oagawa S, Uchida Y, Kobayashi S, Takada K, Terada K, Matsukawa N. [GABA receptor autoimmune encephalitis presenting as transient epileptic amnesia]. Rinsho Shinkeigaku. 2021 Jan 29;61(1):6-11. Japanese. doi: 10.5692/clinicalneurol.cn-001425. Epub 2020 Dec 15. PMID: 33328416.

10. Ma J, Han W, Jiang L. Japanese encephalitis-induced anti-N-methyl-d-aspartate receptor encephalitis: A hospital-based prospective study. Brain Dev. 2020 Feb;42(2):179-184. doi: 10.1016/j.braindev.2019.09.003. Epub 2019 Sep 25. PMID: 31563418.

11. Tanaka K, Kawamura M, Sakimura K, Kato N. Significance of Autoantibodies in Autoimmune Encephalitis in Relation to Antigen Localization: An Outline of Frequently Reported Autoantibodies with a NonSystematic Review. Int J Mol Sci. 2020 Jul 13;21(14):4941. doi: 10.3390/ijms21144941. PMID: 32668637; PMCID: PMC7404295.

12. Ma X, Yin Q, Zeng Z, Wang C, Yang Y, Guo S. Thyroid Function and Autoimmune Indications in Patients with Anti-N-Methyl-D-Aspartate Receptor Encephalitis. Neuroimmunomodulation. 2018;25(2):110-117. doi: 10.1159/000492179. Epub 2018 Aug 29. PMID: 30157483. 
13. Christie LJ, Loeffler AM, Honarmand S, Flood JM, Baxter R, Jacobson S, Alexander R, Glaser CA. Diagnostic challenges of central nervous system tuberculosis. Emerg Infect Dis. 2008 Sep;14(9):1473-5. doi: 10.3201/eid1409.070264. PMID: 18760024; PMCID: PMC2603083.

14. Gowda VK, Nagarajan B, Shivappa SK, Benakappa N. Seropositive Anti-NMDAR Mediated Autoimmune Encephalitis. Indian J Pediatr. 2020 Nov;87(11):961. doi: 10.1007/s12098-020-03312-0. Epub 2020 May 13. PMID: 32405773.

15. Frieling T, Kreysel C, Blank M, Müller D, Melchior I, Euler P, Kuhlbusch-Zicklam R, Haarmeier T, Schemann M. Autoimmune encephalitis and gastrointestinal dysmotility: achalasia, gastroparesis, and slow transit constipation. Z Gastroenterol. 2020 Oct;58(10):975-981. English. doi: 10.1055/a-1233-2190. Epub 2020 Oct 9. PMID: 33036051.

16. Elgendy M, Bhattacharjee S, Weatherby SJ, Lashley DJ. A rare cause of encephalitis with hypothermia and hyponatremia. Acta Neurol Belg. 2020 Oct;120(5):1245-1246. doi: 10.1007/s13760-020-01390-7. Epub 2020 Jun 5. PMID: 32504381.

17. Dutra LA, Abrantes F, Toso FF, Pedroso JL, Barsottini OGP, Hoftberger R. Autoimmune encephalitis: a review of diagnosis and treatment. Arq Neuropsiquiatr. 2018 Jan;76(1):41-49. doi: 10.1590/0004282X20170176. PMID: 29364393.

18. Platt MP, Bolding KA, Wayne CR, Chaudhry S, Cutforth T, Franks KM, Agalliu D. Th17 lymphocytes drive vascular and neuronal deficits in a mouse model of postinfectious autoimmune encephalitis. Proc Natl Acad Sci U S A. 2020 Mar 24;117(12):6708-6716. doi: 10.1073/pnas.1911097117. Epub 2020 Mar 11. PMID: 32161123; PMCID: PMC7104239.

19. Sharma M, Sood D, Chauhan NS, Negi P. Acute necrotizing encephalopathy of childhood. Neurol India. 2019 Mar-Apr;67(2):610-611. doi: 10.4103/0028-3886.257990. PMID: 31085896.

20. Kobayashi Y, Kanazawa H, Hoshino A, Takamatsu R, Watanabe R, Hoshi K, Ishii W, Yahikozawa H, Mizuguchi M, Sato S. Acute necrotizing encephalopathy and a carnitine palmitoyltransferase 2 variant in an adult. J Clin Neurosci. 2019 Mar;61:264-266. doi: 10.1016/j.jocn.2018.11.045. Epub 2018 Nov 22. PMID: 30470651.

21. Biswas A, Varman M, Gunturi A, Yoganathan S, Gibikote S. Teaching Neurolmages: Acute necrotizing encephalopathy of childhood: Neuroimaging findings. Neurology. 2018 Jan 9;90(2):e177-e178. doi: 10.1212/WNL.0000000000004800. PMID: 29311376.

22. Williams TA, Brunsdon RK, Burton KLO, Drevensek S, Brady C, Dale RC, Mohammad SS. Neuropsychological outcomes of childhood acute necrotizing encephalopathy. Brain Dev. 2019 Nov;41(10):894-900. doi: 10.1016/j.braindev.2019.07.007. Epub 2019 Jul 31. PMID: 31376945.

23. Lee YJ, Hwang SK, Kwon S. Acute Necrotizing Encephalopathy in Children: a Long Way to Go. J Korean Med Sci. 2019 May 20;34(19):e143. doi: 10.3346/jkms.2019.34.e143. PMID: 31099193; PMCID: PMC6522889.

24. Abdelrahman HS, Safwat AM, Alsagheir MM. Acute necrotizing encephalopathy in an adult as a complication of H1N1 infection. BJR Case Rep. 2019 Nov 15;5(4):20190028. doi: 10.1259/bjrcr.20190028. PMID: 31938561; PMCID: PMC6945259.

\section{Figures}




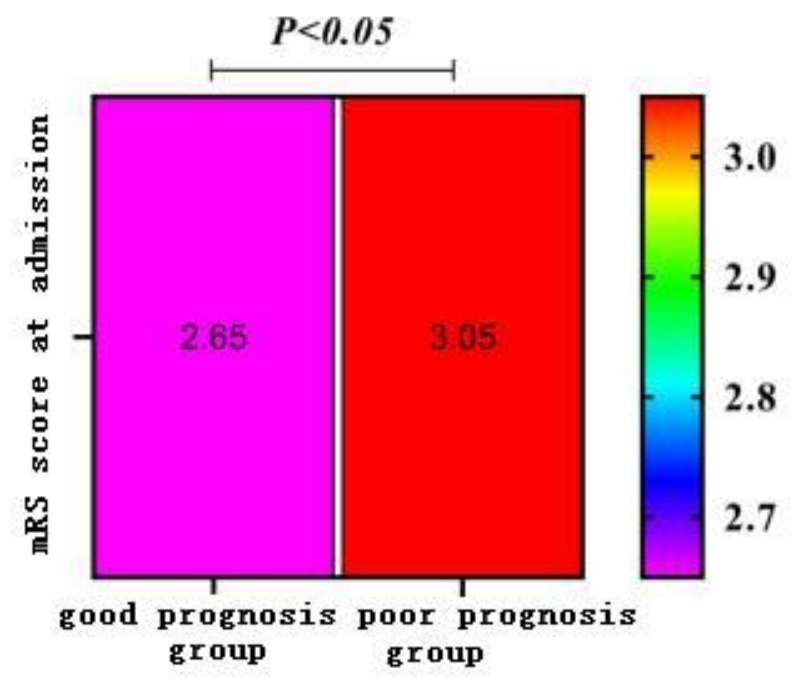

Figure 1

Comparison of mRS scores at admission between two groups 